\title{
Nanoscale
}

PAPER
D) Check for updates

Cite this: Nanoscale, 2019, 11, 9498

\section{Multiphoton fluorescence lifetime imaging microscopy (FLIM) and super-resolution fluorescence imaging with a supramolecular biopolymer for the controlled tagging of polysaccharides $\uparrow$}

\author{
Haobo Ge, $\$^{a}$ Fernando Cortezon-Tamarit, (D) $t^{a}$ Hui-Chen Wang, $t^{a}$ \\ Adam C. Sedgwick, (D) $t^{\mathrm{b}}$ Rory L. Arrowsmith, ${ }^{a}$ Vincenzo Mirabello, (D) a \\ Stanley W. Botchway, ${ }^{c}$ Tony D. James (D) *a and Sofia I. Pascu (D)*a
}

\begin{abstract}
A new supramolecular polysaccharide complex, comprising a functionalised coumarin tag featuring a boronic acid and $\beta$-D-glucan (a natural product extract from barley, Hordeum Vulgare) was assembled based on the ability of the boronate motif to specifically recognise and bind to 1,2- or 1,3-diols in water. The complexation ratio of the fluorophore:biopolymer strand was determined from fluorescence titration experiments in aqueous environments and binding isotherms best described this interaction using a $2: 1$ model with estimated association constants of $K_{\mathrm{a} 1}^{2: 1}=5.0 \times 10^{4} \mathrm{M}^{-1}$ and $K_{\mathrm{a} 2}^{2: 1}=3.3 \times 10^{11} \mathrm{M}^{-1}$. The resulting hybrid (denoted $5 \propto \beta$-D-glucan) was evaluated for its cellular uptake as an intact functional biopolymer and its distribution compared to that of the pinacol-protected coumarin boronic acid derivative using two-photon fluorescence lifetime imaging microscopy (FLIM) in living cells. The new fluorescent $\beta$-D-glucan conjugate has a high kinetic stability in aqueous environments with respect to the formation of the free boronic acid derivative compound $\mathbf{5}$ and retains fluorescence emissive properties both in solution and in living cells, as shown by two-photon fluorescence spectroscopy coupled with time-correlated single photon counting (TCSPC). Super-resolution fluorescence imaging using Airyscan detection as well as TM AFM and Raman spectroscopy investigations confirmed the formation of fluorescent and nano-dimensional aggregates of up to $20 \mathrm{~nm}$ dimensions which self-assemble on several different inert surfaces, such as borosilicate glass and mica surfaces, and these aggregates can also be observed within living cells with optical imaging techniques. The cytoplasmic distribution of the 5 $\mathrm{a} \beta$-Dglucan complex was demonstrated in several different cancer cell lines (HeLa and PC-3) as well as in healthy cells (J774.2 macrophages and FEK-4). Both new compounds (pinacol protected boronated coumarin) 5-P and its complex hybrid $5 \propto \beta-D$-glucan successfully penetrate cellular membranes with the minimum morphological alterations to cells and distribute evenly in the cytoplasm. The glucan biopolymer retains its activity towards macrophages in the presence of the coumarin tag functionality, demonstrating the potential of this natural $\beta$-D-glucan to act as a functional self-assembled theranostic scaffold capable of mediating the delivery of anchored small organic molecules with imaging and drug delivery applications.
\end{abstract}

Received 21st December 2018, Accepted 1st April 2019

DOI: $10.1039 / c 8 n r 10344$ e

rsc.li/nanoscale

\section{Introduction}

\footnotetext{
${ }^{a}$ Department of Chemistry, University of Bath, Claverton Down, Bath, BA2 7AY, UK. E-mail: s.pascu@bath.ac.uk

${ }^{b}$ Department of Chemistry, University of Texas at Austin, 105E, 24th Street, Austin, TX, 78712-1224, USA

${ }^{c}$ Central Laser Facility, STFC Rutherford Appleton Laboratory, and Research Complex at Harwell, Harwell Campus, Didcot, OX11 OQX, UK

$\dagger$ Electronic supplementary information (ESI) available: Super-resolution imaging, multiphoton FLIM data, binding affinities determination, experimental synthetic section. See DOI: 10.1039/c8nr10344e

\$These joint-first authors contributed equally to the manuscript.
}

Natural polysaccharide biopolymers such as $\beta$-D-glucans have been used in a variety of applications including as adjuvants for foods,${ }^{1}$ medicines, ${ }^{2}$ cosmetics ${ }^{3}$ and healthcare products. ${ }^{4}$ Recently, they have been used successfully in particulate forms as delivery agents/adjuvants in vaccines, and highlighted when fragmented in sizes of $c a .300 \mathrm{~nm}$ and combined with ssDNA to prepare nanoparticles as potential vectors for gene and drug 
delivery ${ }^{5}$ and, for the case of the glucan isolated from the cell walls of Saccharomyces cerevisae, to encapsulate antigen models and create vaccination models for fungal infections, ${ }^{6}$ or as a component of immunisation media in protocols against hepatitis $\mathrm{B}$ following in vitro and in vivo testing. ${ }^{7,8}$

The formation of either single or triple helical structures in solvents with differing polarities is of particular interest to investigate the structural properties of $\beta$-D-glucans. ${ }^{9}$ This ability propelled the application of $\beta$-D-glucans in drug delivery for nanomedicine. Functional polysaccharides including glucans are currently used as gels, nanoparticles, microparticles and complexed with other nanomaterials to reduce their toxicity in vitro and in vivo. ${ }^{10-13}$ In addition, polysaccharides such as dextrans ${ }^{10,11}$ and $\beta$-D-glucans have been demonstrated to have a significant role on the immune system with regards to anticancer/anti-tumour effects. ${ }^{14-18}$ Recently the encapsulation for drug delivery against Leishmaniasis (an infection caused by protozoa parasite) using beta glucan particles extracted from Saccharomyces cerevisae was reported in in vitro tests, whereby glucan particles are used as they target macrophages, due to the dectin-1 receptor in their membranes, the main target of common anti-Leishmaniasis drugs. ${ }^{19}$

We have been interested in the development of functional small molecule or nanomaterials as fluorescence probes for bioimaging, theranostics for cancer targeting applications or for the detection of biologically relevant analytes owing to their high sensitivity, selectivity and high spatial and temporal resolution. $^{20-23}$ Recently, we have focussed on sub-cellular studies with imaging agents including boronic-acid tagged fluorescence probes anchored onto glucan bound carbon nanomaterials. ${ }^{12}$ Pioneering work by Shinkai et al. have previously reported hierarchical assemblies of glucan bound carbon nanotubes utilising boronic acid/polysaccharide supramolecular nanocomplexes. ${ }^{24}$ Work focussed on targeted dextrans and glucans as drug delivery devices acting as polymer micelles has also attracted attention since biopolymers can be useful scaffolds for future nanotheranostics: interestingly, the encapsulation of phthalocyanine loaded particles in glucan (the curdlan variety) by DMSO treatments of both components for their application in NIR irradiation of cancer cells was reported in HeLa cells. ${ }^{25}$ Crucially, the antitumour effect of beta glucan nanoparticles was demonstrated in metastatic melanoma in the lung via an entirely novel mechanism. $^{26}$

Due to the emergence of these applications in biological arenas, ranging from ability to target cells and microorganisms there is a pressing need to tailor and control the functionalisation of such biopolymers in water. The incorporation of fluorophore tags with minimum synthetic effort whilst retaining biocompatibility and potential for additional functionalisation, whether covalently or supramolecularly, remains the holy-grail. Natural polysaccharides such as $\beta$-D-glucan (from barley, Hordeum Vulgare) have a large number of 1,2- and 1,3diol units available for binding to boronic acids, their mole- cular recognition chemistry and an understanding of their ability to self-organise from random coils to tubular triple helix structures at the interface between organic solvents and water has been crucial in the design and discovery of new sensing and imaging systems. ${ }^{24}$

We designed our modular system with imaging units (fluorophores), targeting groups (boronic acid $\beta$-D-glucan complex) as well as an amine ( ${ }^{t}$ Boc protected) on which to attach and transport appropriate theranostics drug molecules into cells using simple and effective building blocks: Sivakuma and Wang $^{27}$ reported that a copper(I)-catalysed 1,3dipolar cycloaddition ('click') with non-fluorescent 3-azidocoumarin and terminal alkynes resulted in the formation of highly fluorescent 1,2,3-triazole products (Scheme 1 and $\mathrm{ESI} \dagger$ ). This inspired us to synthesise a new boronic acid building block to generate an in vitro fluorescence imaging probe. ${ }^{23,28-30}$ Boronic acid recognition of diols gave rise to
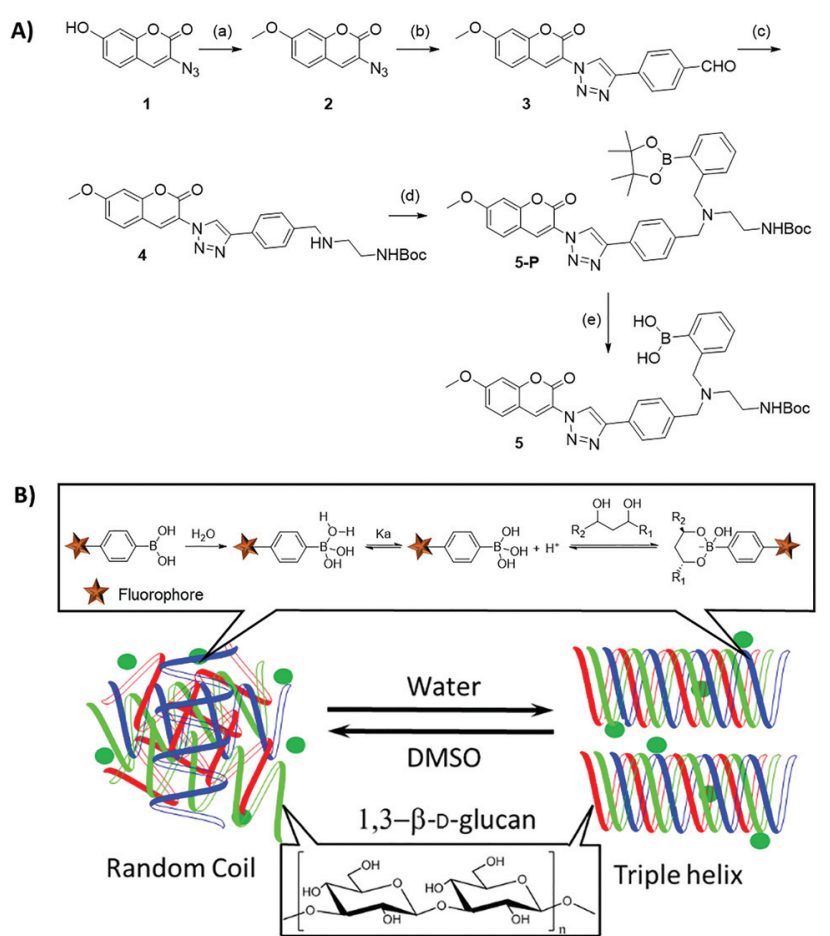

Scheme 1 (A) Synthesis of the pinacol-protected coumarin monoboronate ester of 5-P: (a) Mel, $\mathrm{K}_{2} \mathrm{CO}_{3}$, acetone, reflux. (100\%) (b) 4-ethynylbenzaldehyde 2, $\mathrm{CuSO}_{4} \cdot 5 \mathrm{H}_{2} \mathrm{O}(5 \mathrm{~mol} \%), \mathrm{NaAsc}(10 \mathrm{~mol} \%), \mathrm{H}_{2} \mathrm{O} / \mathrm{EtOH}=$ $1: 1$, rt. $(80 \%)$ (c) (i) mono Boc-diamine (1 eq.), $\mathrm{DCM} / \mathrm{MeOH}$, rt. (ii) $\mathrm{NaBH}_{3} \mathrm{CN}, \mathrm{MeOH}$, rt. (74\%) (d) 2-(bromomethyl)phenylboronic acid pinacol ester, $\mathrm{K}_{2} \mathrm{CO}_{3}, \mathrm{ACN}$, reflux. (B) Schematic representation of the $\beta$-D-glucan triple helix in water and the diagram of boronic acid fluorophore reversible binding with the diols of the 1,3- $\beta$-D-glucan. Pinacol deprotection of 5-P proceeded to 5 in situ in presence of glucan diols, at $\mathrm{pH} 8-9.5$ to form the desired diol-boronate and covalently-bonded supramolecular biopolymer complex, denoted 5@ $\beta$-D-glucan. The mechanism of formation likely involves exchanges under thermodynamic control: boronic acid-diol recognition event coupled with a single coil/triple helix rearrangement of the glucan chains at the interface between DMSO/aqueous media (footnote 1 and ref. 12). 
some rapid and highly selective recognition chemistry that has been used in bio-conjugation and bio-imaging research. ${ }^{31-35}$

Previous studies have indicated that borate anions form covalently-bonded complexes with diol groups of the $\beta$-D-glucan at ca. $\mathrm{pH} 8-9.5{ }^{42}$

Furthermore, while fluorescent probes offer high sensitivity, natural biological molecules such as coumarin absorb mainly UV light effectively and many of them are also emissive in the UV. This gives rise to two problems (a) absorption and scattering of UV and Vis light by the sample limits the depth of sample that can be imaged (b) emission of light by the sample (autofluorescence) limits probe signal:background ratios. Since biological samples absorb less strongly with increasing wavelength, excitation with red light and multiphoton imaging by near infra-red light may be used to reduce the magnitude of these problems. In earlier work, we demonstrated that metal species with long luminescence lifetimes can be used in timeresolved experiments that effectively reject scatter and short lived fluorescence from the sample as well as report on the fate/stability of the metal complex. One of the main limitations for in vivo optical imaging is absorption by haem in blood which blocks out the $450-550 \mathrm{~nm}$ region: it is essential to shift to NIR excitation (e.g. at $810 \mathrm{~nm}$ and 2 photon excitation) to avoid or to significantly minimise this, in addition to taking advantage of the enhanced tissue penetration in the NIR. Our previous work explored both time-gating methodologies (fluorescence lifetime microscopy, FLIM), and the application of novel probes for long wavelength using two-photon (2P) excitation, including the applications of fluorescein-boronic acids, naphthylimine-boronic acids and coumarin-boronic acids for interaction with cells. Time gating provides a method to observe a molecular species by a change in its excited state, for example, we demonstrated in recent studies that a fluorescent free ligand has a significantly different lifetime to its bound form, and, depending on the systems involved, the boundunbound metal-ligand complexes can show fluorescence lifetimes that differ significantly. We have already shown that it is possible to use 2P FLIM techniques to monitor the cellular fate of kinetically stable $2 \mathrm{P}$ fluorescent carbon nanomaterials and small molecules structurally related to derivatives that are clinically used for imaging and therapy, e.g. BODIPY-tagged thiosemicarbazones similar to known hypoxia tracers in clinical trials for oncology applications. ${ }^{36}$ We report here a new approach for the self-assembly of a functional, fluorescent $\beta$-Dglucan and on the behaviour of the resulting biopolymer in thin film and in cellular environments by a number of microscopies to probe the hypothesis that the resulting fluorescent, coumarin-tagged hybrid connected through boronic acid-diol interactions can act as an intact object in the cellular environment.

\section{Results and discussion}

The boronic acid coumarin derivative 5-P, was first synthesised over four steps as shown in Scheme 1, and further described in the ESI. $\uparrow$ Initially, the hydroxyl group of Compound 1 was alkylated using $\mathrm{MeI}$ and $\mathrm{K}_{2} \mathrm{CO}_{3}$. The potential for additional functionalisation of the system using the protected ${ }^{t} \mathrm{Boc}$ amine group makes this system a useful labelling agent for bioimaging experiments, and opens up the possibility of further bio-orthogonal derivatisation. ${ }^{13,37}$ This step was carried out to avoid any possible side reactions occurring from the free hydroxyl group. Compound 2 was then subjected to standard 'click' conditions with 4-ethynylbenzaldehyde to afford the highly fluorescent 1,2,3-triazole intermediate 3. Reductive amination with tert-butyl(2-aminoethyl)carbamate and 3 using $\mathrm{NaBH}_{3} \mathrm{CN}$ in $\mathrm{MeOH}$ afforded amine 4 in a good yield (73\%). Compound 4 was then alkylated using 2-(bromomethyl) phenyl boronic acid pinacol ester, to afford the desired boronic acid in a protected form, as the pinacol ester (denoted 5-P) of the coumarin derivative $\mathbf{5}$ (ESI $\dagger$ ). Fluorescence spectroscopic analysis of $\mathbf{5}$ was carried out in a number of organic solvents (DMSO, $\mathrm{MeOH}$ ) under a number of excitation wavelengths and under both $1 \mathrm{P}$ and $2 \mathrm{P}$ excitation and its ability to bind saccharides was then evaluated using several simple sugar monomers in an aqueous environment [ESI $\dagger$ ]. Consistent with previously published work, the binding between 5 and 1,3- $\beta$-D-glucan was studied in situ using the 5-P derivative, which is a boronic acid pinacol ester coumarin known to undergo rapid transesterification with saccharides. ${ }^{42}$ The derivative 5-P is a highly sterically hindered thermodynamically stable boronate ester of pinacol with very weak kinetic stability in presence of saccharides and at $\mathrm{pH}$ 8.2-9.5 and has been widely used as part of synthetic platforms for fluorescent sensors based on boronic acids generated in situ. ${ }^{38-42}$

Compound 5-P displayed a weak fluorescence emission response towards these monosaccharides in general and showed only a small fluorescence emission increase with D-fructose, almost no change with D-glucose, while D-galactose and D-mannose resulted in a measurable fluorescence decrease (ESI $\dagger$ ). As expected, the recognition and binding of the boronic acid fluorophore to the 1,3-diol groups of $\beta$-D-glucan (represented in Scheme 1, B) was found to be enhanced under the basic $\mathrm{pH}$ conditions used. ${ }^{38-42}$

No fluorescence emission in the control samples of free $\beta$-Dglucan in aqueous solvents was detected. The interaction of compound 5-P with $\beta$-D-glucan in water or phosphate buffer solution $(\mathrm{PB})$ resulted in the slight reduction of the coumarin fluorescence intensity in solution, i.e. the fluorescence of coumarin-tagged protected boronic acid 5 was quenched upon addition of $\beta$-D-glucan with respect to the free fluorophore (Fig. 1). This allowed the fluorescence titrations carried out to elucidate the level of binding affinity between 5 and $\beta$-D-glucan (ESI $\dagger$ ) and predict whether or not the resulting functional biopolymer would withstand cellular uptake challenges, and remains traceable by optical imaging.

A simplified model to evaluate the binding of 5 to $\beta$-Dglucan and glucose through single photon fluorescence spectroscopy (ex. $350 \mathrm{~nm}$ ) is reported in the ESI $\dagger$ and suggests a similar affinity of 5 for the two systems. The $K_{\mathrm{a}}^{1: 1}$ were first cal- 

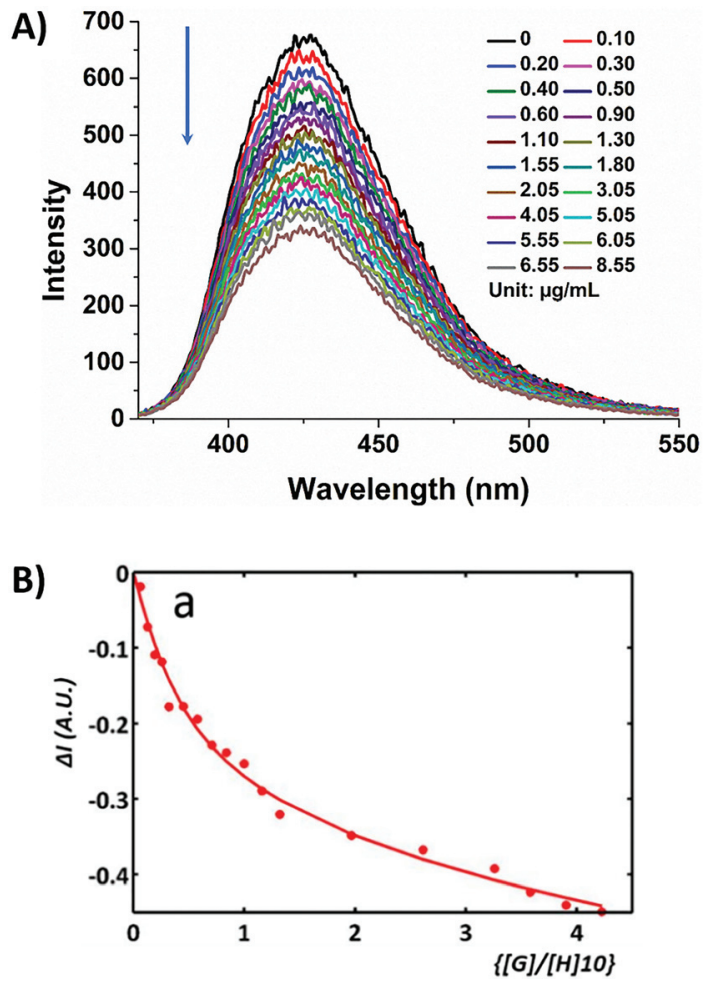

Fig. 1 (A) Fluorescence titration of $\beta$-D-glucan ( $1 \mathrm{mg} \mathrm{ml}^{-1}$ dissolved in $\mathrm{PB})$ into a solution of (protected) compound $5\left(1 \times 10^{-7} \mathrm{M} 5-\mathrm{P}\right.$ in DMSO) showing the decrease in fluorescence intensity; final measured $\mathrm{pH}$ was $8.4 ; \lambda_{\text {ex }} 350 \mathrm{~nm}$. (B) Corresponding binding isotherm model adapted for the formation of the complex $5 \propto \beta-D$-glucan system $2: 1$ model fitting, $K_{\mathrm{a} 1}^{2: 1}=5.0 \times 10^{4} \mathrm{M}-1, K_{\mathrm{a} 2}^{2: 1}=3.3 \times 10^{11} \mathrm{M}-1 ; \Delta I=\left(I_{\exp }-I_{\text {cal }}\right)$.

culated to be $6.3 \times 10^{7} \mathrm{M}^{-1}$ and $6.5 \times 10^{7} \mathrm{M}^{-1}$ respectively (ESI, Fig. S25 $\dagger$ ). ${ }^{27-29}$ A more complex fitting model has been investigated for the formation of complex 5@ $\beta$-D-glucan by analogy with published methods describing different possible arrangements of two molecular species, reported by Jabbari-Farouji and van der Schoot. ${ }^{43}$ The interactions between 5-P and $\beta$-Dglucan giving rise to $1: 1,1: 2$ or $2: 1$ complexes seemed most plausible, according to the isotherm binding models reported by Thordarson and resulting in association binding constants, $K_{\mathrm{a}}$ (Fig. 1 and ESI, Tables S1-S3†). ${ }^{44,45}$ The binding constant for the $1: 1$ binding model $\left(K_{\mathrm{a}}^{1: 1}\right)$ of coumarin boronic acid with $\beta$-D-glucan was calculated to be $2.5 \times 10^{8} \mathrm{M}^{-1}$. The $2: 1$ binding model resulting in the formation of complex 5@ $\beta$-Dglucan showing a positive cooperativity with $K_{\mathrm{a} 1}^{2: 1} \gg K_{\mathrm{a} 2}^{2: 1}\left(K_{\mathrm{a} 1}^{2: 1}=\right.$ $5.0 \times 10^{4} \mathrm{M}^{-1} ; K_{\mathrm{a} 2}^{2: 1}=3.3 \times 10^{11} \mathrm{M}^{-1}$ ).

These evaluations suggest that in an aqueous environment, the binding of the coumarin molecule to the $\beta$-D-glucan strands favours a second binding event. ${ }^{46}$ Therefore, strong binding constants evaluated for the formation of complex 5 5@-D-glucan encouraged us to consider the complex 5@ $\beta$-Dglucan a suitable candidate for in vitro imaging. Compound 5-P is a small molecule which has hydrophobic and hydrophilic units, including a protected boronic acid unit which has already been proven to be rapidly deprotected in aqueous media: we hypothesised that $\mathbf{5}$ can be internalised via a plasma membrane exchange process likely mediated by the boronic acid-membrane binding in the first instance. ${ }^{47}$

Compound 5-P was investigated for its ability to be internalised by common, living cancerous cells (HeLa and PC-3 cells): these lines were used as model systems to verify uptake and biodistribution both outside the cell membrane and inside the cell. This aspect was visualised by confocal laser scanning fluorescence microscopy (CLSFM) as well as by super-resolution imaging techniques (using the Airyscan detection) and the integrity of the new fluorescent biopolymer in a living cells environment including organelles immobilisation was analysed by multi-photon fluorescence lifetime imaging microscopy (FLIM), which has been found a powerful analytical tool which can bring the fourth dimension, the temporal analysis, in the interactions between imaging probes and their cellular environment. ${ }^{28,48}$ Cellular imaging protocols which have been previously proven successful to lead to the internalisation of a fluorescein-biotin tagged glucan complex ${ }^{12,49}$ and have been adapted hereby for the newly designed functional fluorophore 5. Assays indicated the successful uptake of compound 5-P into HeLa cells after 15 minutes incubation at $37^{\circ} \mathrm{C}$ as well as at $4{ }^{\circ} \mathrm{C}$ as an indicator of passive diffusion rather than an endocytosis-driven uptake mechanism, as in Fig. 3. The slight decrease in the cellular uptake at $4{ }^{\circ} \mathrm{C}$ was likely due to the increase in the plasma membrane viscosity at low temperature, known to shift the cell membrane from a highly fluid state to a highly ordered state reducing the plasma membrane exchange process. ${ }^{50}$

Single photon as well as two-photon confocal fluorescence microscopy imaging indicated that the complex denoted 5 @ $\beta$-D-glucan can be observed during cellular uptake in PC-3 cells (Fig. 3 and ESI $\dagger$ ) and that 5@ $\beta$-D-glucan can successfully pass through the cell membrane and internalise in the cytoplasm of these living cells. This seems to suggest that the $\beta-\mathrm{D}^{-}$ glucan can efficiently target the cell membrane by recognising polysaccharides that are part of the membrane and lead to cellular internalisation. ${ }^{51,52}$ CFM-coupled multiphoton FLIM techniques were applied here to directly visualise the presence of the coumarin fluorophore $\mathbf{5}$ and the level to which its nanobiohybrid denoted 5@ $\beta$-D-glucan remains intact with respect to loss of the boronic acid tag inside cells after the uptake. This technique has been used in previous work to explore the intracellular distribution of complex systems including nanodimensional hybrids by tracing, and comparing, the individual lifetime distributions within cellular compartments. ${ }^{12}$

The use of two-photon fluorescence-lifetime imaging microscopy (FLIM $)^{53}$ allowed the analytical exploration of 5 @ $\beta$-D-glucan integrity in cells, with respect to loss of free compound $\mathbf{5}$ and an investigation into this complex' speciation Fig. 3 shows the fluorescence lifetime maps for compound $\mathbf{5}$ and 5@ $\beta$-D-glucan in HeLa and PC-3 cells, and the corresponding solution TCSPC spectra are given in Fig. 2.

The images in Fig. 4 show there are subtle differences additional to the expected similarities of the fluorescence lifetime components for 5-P and 5@ $\beta$-D-glucan species, observed 


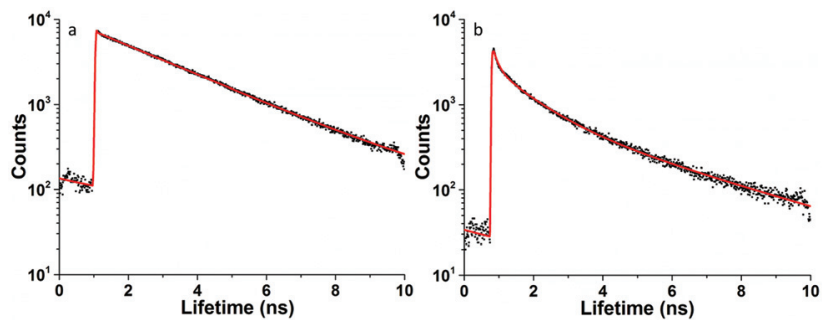

Fig. 2 Two-photon time-correlated single photon counting (TCSPC) $\lambda_{\mathrm{ex}}=810 \mathrm{~nm}$ : (a) compound 5-P: $\chi^{2}=1.22, \tau_{\mathrm{m}}=1.7 \mathrm{~ns}\left(\tau_{1}=0.61 \mathrm{~ns}\right.$ (51.7\%), $\tau_{2}=2.8 \mathrm{~ns}(48.3 \%)$ and (b) $5 \mathrm{a} \beta$-D-glucan $\chi^{2}=1.2, \tau_{\mathrm{m}}=1.4 \mathrm{~ns}$ $\left(\tau_{1}=0.6 \mathrm{~ns}(58.6 \%), \tau_{2}=2.6 \mathrm{~ns}(41.4 \%)\right.$; in DMSO : PB $1: 1: 5-\mathrm{P}\left(1 \times 10-{ }^{7} \mathrm{M}\right)$ and, 5-P $\left(1 \times 10-{ }^{7} M\right)$ measured in presence of excess glucan forming $5 @ \beta$-D-glucan in situ.

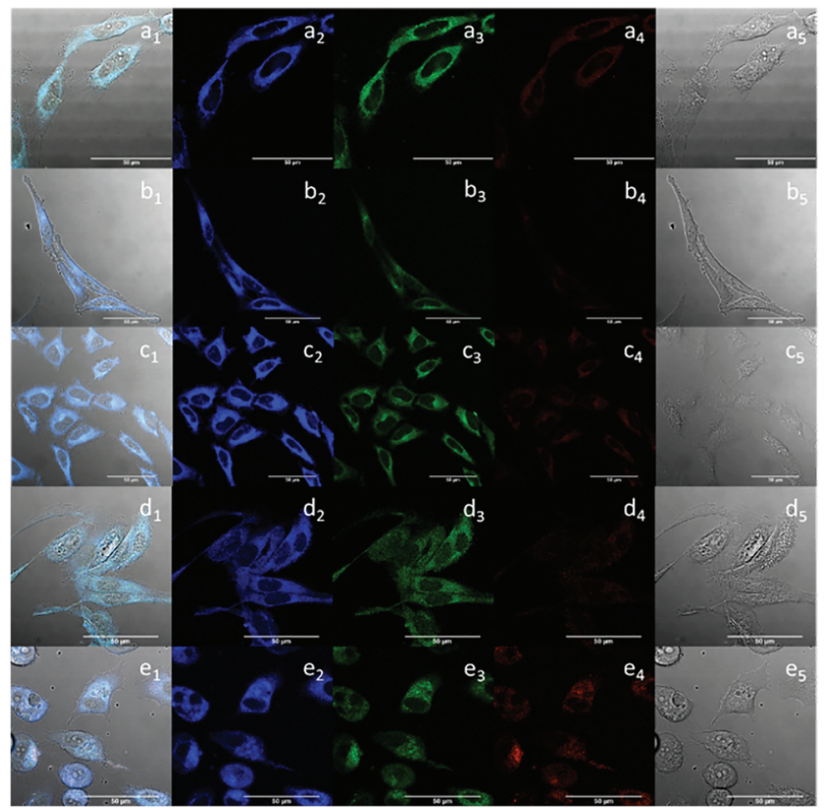

Fig. 3 Single-photon laser-scanning confocal fluorescence imaging of 5-P $\left(100 \mu \mathrm{M}\right.$ in 0.5 : 99.5\% DMSO : RPMI) in HeLa cells at $37{ }^{\circ} \mathrm{C}, 15 \mathrm{~min}$ incubation (a); 5 in HeLa cells at $4{ }^{\circ} \mathrm{C} 15$ min incubation (b); 5@ $\beta$-Dglucan (10 $\mu \mathrm{g} \mathrm{mL}^{-1}$ in glucan; $100 \mu \mathrm{M}$ in 5-P; 0.5 : 99.5\% DMSO : RPMI) in HeLa cells at $4{ }^{\circ} \mathrm{C}, 15$ min incubation (c); 5 in PC-3 cells at $37^{\circ} \mathrm{C}$, 15 min incubation (d); $5 @ \beta$-D-glucan in PC- 3 cells at $37^{\circ} \mathrm{C}, 15 \mathrm{~min}$ incubation (e). Overlapping of the DIC, blue, green and red channels $\left(a_{1}, b_{1}\right.$, $c_{1}, d_{1}$ and $\left.e_{1}\right)$; blue channel, $\lambda_{e m}=420-480 \mathrm{~nm}\left(a_{2}, b_{2}, c_{2}, d_{2}\right.$ and $\left.e_{2}\right)$, green channel, $\lambda_{\mathrm{em}}=516-530 \mathrm{~nm}\left(a_{3}, b_{3}, c_{3}, d_{3}\right.$ and $\left.e_{3}\right)$; red channel $\lambda_{\text {em }}=615-650 \mathrm{~nm}\left(a_{4}, b_{4}, c_{4}, d_{4}\right.$ and $\left.e_{4}\right)$, and DIC channel $\left(a_{5}, b_{5}, c_{5}, d_{5}\right.$ and $\left.e_{5}\right) ; \lambda_{\text {ex }}=405 \mathrm{~nm}$; scale bar: $50 \mu \mathrm{m}$.

under a range of cells and conditions. Lifetime mapping and distributions are presented together with two-photon intensity maps indicating the spatial variations in fluorescence emission and the corresponding lifetime distribution curves for the predominant lifetime component $\left(\tau_{1}\right)$. Full data sets including the contributions of the minor lifetime component $\left(\tau_{2}\right)$ are given in ESI. $\dagger$ The micrographs show that $\mathbf{5}$ and $\mathbf{5} @ \beta$-D-glucan are capable of penetrating the cell membrane both at $4{ }^{\circ} \mathrm{C}$ (Fig. $4 \mathrm{~b}_{1-2}$ and $\mathrm{c}_{1-2}$ ) and $37{ }^{\circ} \mathrm{C}$ (Fig. $4 \mathrm{a}_{1-2}, \mathrm{~d}_{1-2}$ and $\mathrm{e}_{1-2}$ ).

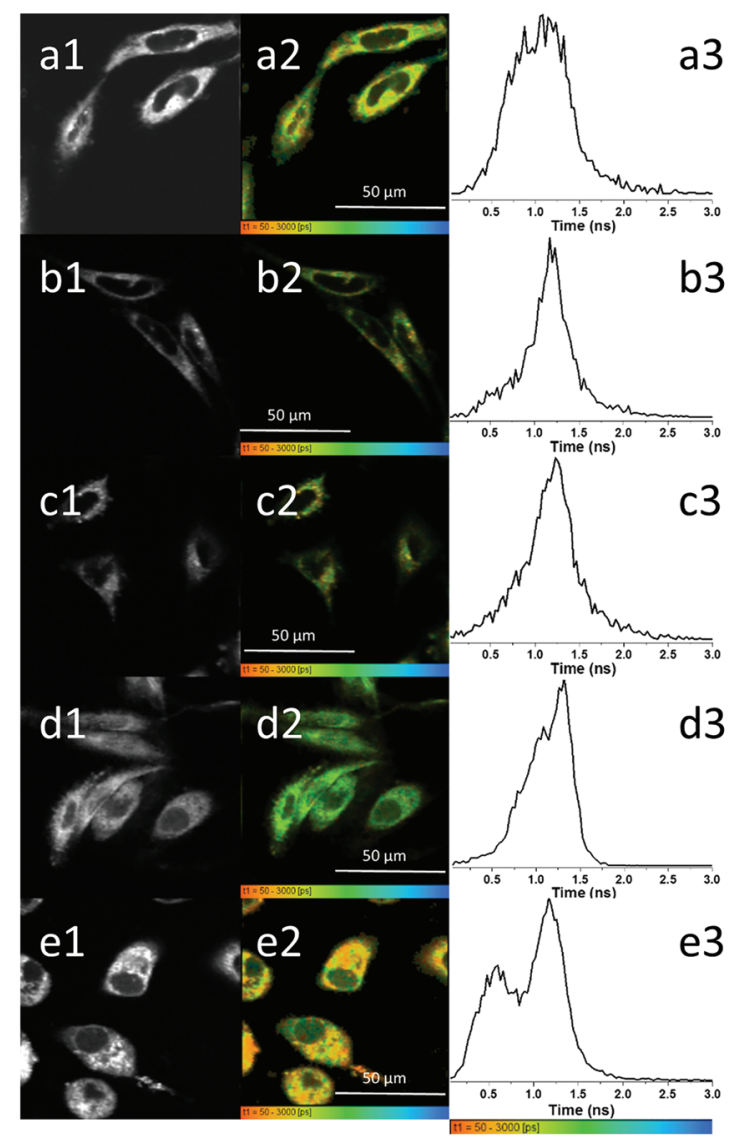

Fig. 4 Two-photon fluorescence imaging including lifetime microscopy mapping of 5-P (100 $\mu \mathrm{M}$ in $0.5: 99.5 \%$ DMSO : RPMI) $\left(a_{1-2}\right.$; $\left.\mathrm{b}_{1-2} ; \mathrm{d}_{1-2}\right)$ and $5 \mathrm{a} \beta$-D-glucan $\left(0.5: 99.5 \%\right.$ DMSO : RPMI) $\left(\mathrm{c}_{1-2} ; \mathrm{e}_{1-2}\right)$ in HeLa $\left(a_{1-2} ; b_{1-2} ; c_{1-2}\right)$ and PC-3 cells $\left(d_{1-2} ; e_{1-2}\right)$ after 15 min incubation. Corresponding fluorescence lifetime distribution curves: $a_{3}, b_{3}, c_{3}, d_{3}$, $\mathrm{e}_{3} ; \lambda_{\mathrm{ex}}=810 \mathrm{~nm}$. Scale bar: $50 \mu \mathrm{m}$. The micrographs show that 5-P and 5 a $\beta$-D-glucan are capable of penetrating the cell membrane at either $4{ }^{\circ} \mathrm{C}\left(b_{1-2} ; c_{1-2}\right)$ or at $37{ }^{\circ} \mathrm{C}\left(a_{1-2} ; d_{1-2} ; e_{1-2}\right)$, although the lower temperature reduces the extent of cellular uptake. Legend colours provide a direct correlation between the lifetime maps a2-e2 and the histograms showing the corresponding lifetimes distribution (a3-e3).

However, the lifetime histograms suggest that the lower temperature reduces the extent of cellular uptake in both cases. For both 5-P and the 5@ $\beta$-D-glucan conjugate, two lifetime components were observed in living cells, under similar assay conditions performed in HeLa.

The first lifetime distribution maxima (corresponding to $\tau_{1}$ ) and its WHH for the 5@ $\beta$-D-glucan $(0.54 \pm 0.27 \mathrm{~ns})$, is similar to that of compound 5-P alone (0.59 $\pm 0.29 \mathrm{~ns})$. In addition, a second lifetime component $\left(\tau_{2}\right)$ for the 5@ $\beta$-D-glucan and 5-P are $2.54 \pm 0.81 \mathrm{~ns}$ and $2.71 \pm 0.51 \mathrm{~ns}$ respectively, suggesting that within the cellular environment the fluorescence lifetime of 5-P is shortened in the presence of $\beta$-D-glucan. A close inspection of lifetime characteristics in single points chosen showed that the relative percentage distributions of the two lifetime components vary across the cells cytoplasm. The ranges observed are as expected for coumarin-based fluorophores and consistent with previous studies. ${ }^{54,55}$ 
Fluorescence lifetime imaging in confocal mode, either in $1 \mathrm{P}$ or $2 \mathrm{P}$ excitation mode alone allows mapping of the region in the cytoplasm where the coumarin boronic acid tag is released upon uptake within the cells. In solution studies the fluorescence lifetime decay curves of 5-P and 5@ $\beta$-D-glucan (measured by the two-photon time-correlated single photon counting technique, TCSPC, $810 \mathrm{~nm}$ excitation, $8 \mathrm{~mW}$ laser) in PB buffer: DMSO 1:1 mixture are markedly different, as seen in Fig. 2. While the longest lifetime $\left(\tau_{2}\right)$ component of a $\mathrm{PB}$ solution of 5-P was calculated to be $2.80 \mathrm{~ns}$ (48.3\%), 5@ $\beta$-Dglucan presented a shorter $\tau_{2}$ of $2.62 \mathrm{~ns}(41.4 \%)$.

The similarities in values of the longest lifetime components $\left(\tau_{2}\right)$ may be explained by the presence of the free coumarin-derivative (5) in solution, in equilibrium with the complexed variant. Furthermore, the shorter lifetime component $\left(\tau_{1}\right)$ is slightly shortened in the presence of $\beta$-D-glucan. The $\tau_{1}$ of 5 and 5@ $\beta$-D-glucan were measured as 0.61 ns $(51.7 \%$ weighting) and $0.60 \mathrm{~ns}$ (58.6\% weighting) respectively. Overall, the average lifetime $\left(\tau_{\mathrm{m}}\right)$ is reduced from $1.67 \mathrm{~ns}$ to $1.43 \mathrm{~ns}$ when the boronic acid tag $\mathbf{5}$ is bound to the $\beta$-D-glucan chains, but the observations are consistent within experiments in solution as well as in cellular media. The trend observed in fluorescence lifetime decay and the changes on the fluorescence emission intensity observed for the titration between the coumarin and $\beta$-D-glucan taken together with cellular FLIM point to the kinetic stability of the $5 @ \beta$-D-glucan adduct and its aggregated material in PBS consistent with titration experiments and earlier observations. ${ }^{12,56,57}$

To verify the formation of complex 5@ $\beta$-D-glucan, Raman spectroscopy investigations were conducted on a 5@ $\beta$-Dglucan, glucan and 5@ $\beta$-D-glucan inside cells, and a robust line of typical healthy cells, and for this, a typical line of macrophages was chosen for a proof-of-concept experiment. The Raman spectrum shows the glycosidic linkages characteristic for $\beta$-glucans (i.e. polysaccharides built from glucose monomers via glycosidic bonds) in the region between 800 and $1000 \mathrm{~cm}^{-1}$, consistent with the studies on a series of carbohydrate monomers showing that $\beta$-type glycosidic linkages appear between 905-885 $\mathrm{cm}^{-1}$ and for $\alpha$-type between 865-835 $\mathrm{cm}^{-1} .^{58}$ The Raman spectra in Fig. 5 indicated that $\beta$-D-glucan has peak at $893 \mathrm{~cm}^{-1}$, which indicates a $\beta$-type glycosidic bonds. However, 5@ $\beta$-D-glucan has two weak peaks 894
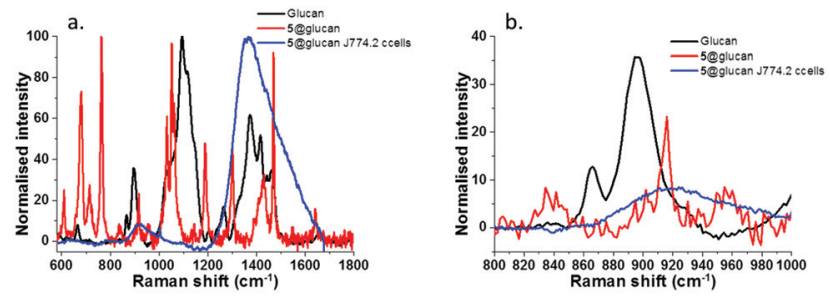

Fig. 5 Raman spectra of: (a) $5 \alpha \beta-D$-glucan and $\beta$-D-glucan on aluminium support and $5 a \beta-D-g l u c a n$ in fixed 3774.2 cells; (b) expanded region $\left(800-1000 \mathrm{~cm}^{-1}\right.$ ) relevant for the presence of functionalised glucan. The peak at $893 \mathrm{~cm}^{-1}$ is diagnostic for the beta-type glycosidic bonds. and $901 \mathrm{~cm}^{-1}$, and a large peak at $916 \mathrm{~cm}^{-1}$, which indicates binding to coumarin produces overlap in these regions. In fixed macrophage cells with 5@ $\beta$-D-glucan, a similar broad peak around $920 \mathrm{~cm}^{-1}$ was observed, which indicates the existence of the 5@ $\beta$-D-glucan. Thus, for the first time Raman spectroscopy on solid supports was carried out on such composites, to confirm the formation of the beta-type glycosidic bonds involving [O-B-O] unit (Fig. 5 and ESI $\dagger$ ) in thin film and fixed cells.

To complement this analysis on thin film aggregates, we visualised fluorescent micellar-like aggregates down to ca. $100 \mathrm{~nm}$ scale, we performed further imaging on the complexed fluorescent nano-conjugates by tapping mode AFM (TM-AFM). This imaging was performed on the coumarin-glucan nanohybrids as well as in the unfunctionalised $\beta$-D-glucan biopolymer (Fig. 6). The samples were spin-coated at $3000 \mathrm{rpm}$ from solutions of $c a .1 \mathrm{mg} \mathrm{mL} \mathrm{m}^{-1}$ concentration and imaged to show complementary information on the nature of the supramolecular aggregation of this biopolymer in thin film. AFM images suggest that the formation of the coumarin-glucan nanohybrid contributes to the aggregation in particles with a homogenous size distribution of 10-25 nm (Fig. 6) when compared to the $\beta$-D-glucan alone (see ESI $\dagger$ ), where the formation of aggregates is also observed but the distribution of sizes and

a)
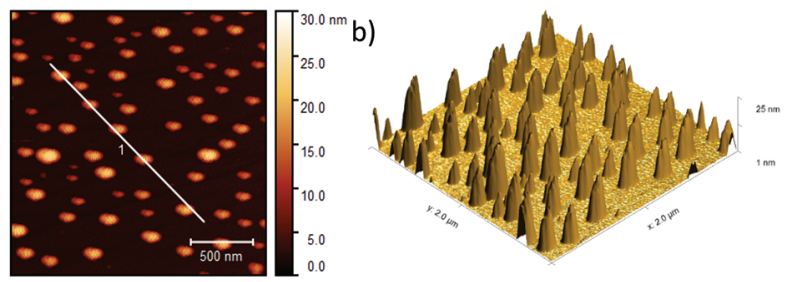

c)

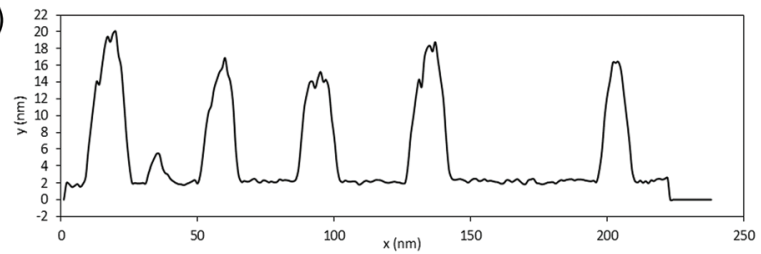

d)
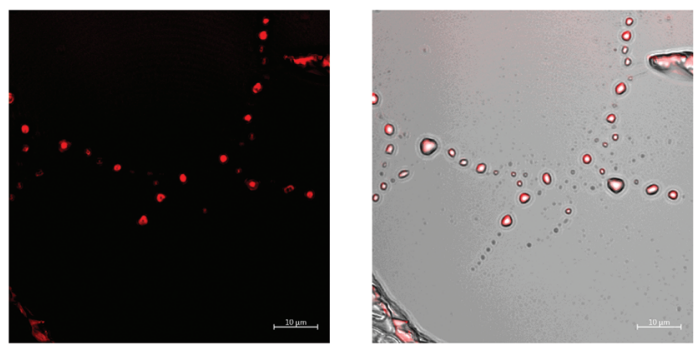

Fig. 6 (a) Tapping mode AFM image of coumarin-glucan conjugate spin coated (3000 rpm) onto a mica substrate; (b) 3D tapping mode image of coumarin-glucan conjugate; (c) height profile analysis under white line in (a), showing formation of nano-biopolymer $5 \propto \beta$-D-glucan of ca. $20 \mathrm{~nm}$ size; (d) super-resolution airyscan confocal microscopy images, red channel (left) and overlapping image of DIC and red channel (right). Scale bar: $10 \mu \mathrm{m}$. 
a.

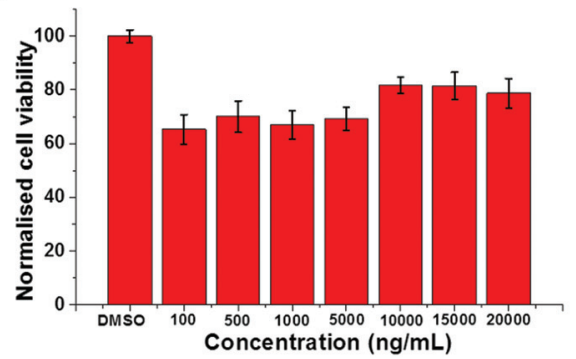

b.

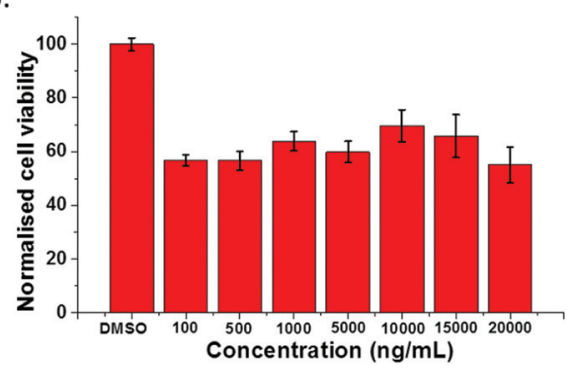

Fig. 7 Normalised cell viability test of macrophage cells (J774.2 cell line, from mouse) treated with (a) dispersed 5@ $\beta$-D-glucan at high concentration up to $2 \mathrm{mg} \mathrm{mL}^{-1}$ and (b) $\beta$-D-glucan alone at high concentration up to $2 \mathrm{mg} \mathrm{mL}^{-1}$. Experiments at each of the concentrations used were repeated six times, error bars stands for standard error calculated from six repeated measurements.

shapes seems to be broader. This allowed us to observe the presence of these tower-like biopolymers down to the $30 \mathrm{~nm}$ range and the observations are consistent with those from earlier investigations on this barley extract. We also observed the occurrence of a red-shift in the emitted fluorescence of the 5@ $\beta$-D-glucan aggregates at high concentration, when observed as deposited on borosilicate glass by single photon confocal fluorescence, and investigated these aggregates using superresolution imaging with Airyscan detection (Fig. 6).

Measurements from FLIM, Raman and CFM backed by binding experiments in solution are in agreement that 5@ $\beta$-Dglucan is a fluorescent supramolecular biopolymer capable of uptake both in typical, living cancerous cells (PC-3 or HeLa) and non-cancerous cells (FEK-4, ESI, $\uparrow$ or a typical macrophages cell line) as an intact aggregate, however, FLIM seems to suggest that in areas of cellular cytoplasm both the free, and the conjugated fluorophore can be found.

To identify whether or not the function of the glucan was retained upon coumarin-boronic acid functionalisation, cell viability tests were also performed in the J774.2 Macrophage cell line. For this experiment, stock solutions of 5, 5@ $\beta$ - $\mathrm{D}^{-}$ glucan and $\beta$-D-glucan were prepared at 8 different concentrations between $250 \mu \mathrm{M}$ to $1 \mathrm{nM}$ and $10 \mu \mathrm{g} \mathrm{mL} \mathrm{m}^{-1}$ to $1 \mathrm{pg} \mathrm{mL}^{-1}$ respectively. A general reduction in the population of cells compared with the DMSO control was observed (Fig. 7 and ESI $\dagger$ ). The cell viability rate dropped only when the concentration of 5-P increased. In contrast, the cell viability rate increased significantly when the concentration of $\beta$-D-glucan increased. Interestingly the MTT assays involving 5@ $\beta$-Dglucan showed that with an increase of concentration, the cell viability rate gradually increases peaking at $10 \mu \mathrm{g} \mathrm{mL}{ }^{-1}$.

This result seems to suggest that when compound $\mathbf{5}$ is bound to $\beta$-D-glucan the resulting species 5@ $\beta$-D-glucan combines the mild toxicity emerging from the coumarin unit as well as the function of enhancing cell viability well known from $\beta$-D-glucan. Fig. 7b shows the similar results obtained for sets of higher concentrations of $5 @ \beta$-D-glucan and $\beta$-D-glucan of up to $2 \mathrm{mg} \mathrm{mL}^{-1}$ introduced to macrophage cells. This indicated $\beta$-D-glucan is generally a non-toxic material to target cells and able to improve the biocompatibility of a coumarin tag with a boronic acid unit.

\section{Conclusions}

A fluorophore based on a new boronic acid derivative of coumarin and its corresponding $\beta$-D-glucan supramolecular conjugate were prepared and investigated by optical fluorescence techniques (one-photon and two-photon fluorescence spectroscopy together with time correlated singlephoton counting), AFM and Raman. The binding of this functional boronic acid to $\beta$-D-glucan from barley produced a kinetically stable nano-dimensional, soft material composite, denoted 5@ $\beta$-D-glucan, with a binding affinity allowing for the retention of the complexed state even upon cellular uptake over a range of concentrations. Solution phase investigations by fluorescence spectroscopies both in single photon and two-photon excitation modes combined with in vitro studies (in HeLa and PC-3 cells, macrophage). The supramolecular conjugate was also evaluated as cellular imaging probes in different cancer cell lines (HeLa and PC-3) as well as J774.2 macrophages using single- and two-photon fluorescence lifetime imaging microscopy (FLIM) showing that the conjugates enter cells successfully; studies by multiphoton fluorescence confocal imaging and super-resolution imaging indicate that both 5-P and 5@ $\beta$-D-glucan can enter cells and distribute in the cytoplasm at both $37{ }^{\circ} \mathrm{C}$ and $4{ }^{\circ} \mathrm{C}$. Fluorescence lifetime studies confirmed for the first time the successful binding of a coumarin boronic acid with $\beta$-D-glucan which remains intact as a kinetically stable complex in aqueous environments.

We describe a new coumarin-appended boronate ester as a fluorogenic reagent, which binds to both mono and polysaccharides. This new glucan hybrid could serve as cellular imaging probe: a simple coumarin boronic acid can thus act to bridge the gap between the development and application of small molecules and bio-nanomaterials for the labelling of living cancer cells. ${ }^{59}$ We believe that biopolymers such as $\beta$-D-glucan from barley used as a scaffold for boronate-tagging methodologies could lead to new synthetic approaches to deliver non-invasive and affordable early diagnostics for cancers which are difficult to access non-invasively such as prostate cancers. 


\section{General methods}

All chemical reagents and solvents were analytical grade and purchased from commercial suppliers. ${ }^{1} \mathrm{H}$ NMR and ${ }^{13} \mathrm{C}$ NMR spectra were recorded on the Bruker AV-300 and AV-400 spectrometer with chemical shifts reported in $\mathrm{ppm}\left(\mathrm{CDCl}_{3}\right.$, TMS as internal standard) at room temperature. Mass spectrometry was recorded on an HP 1100 LC-MS spectrometer. UV-vis absorption spectra were recorded on a Varian Cary 100 spectrophotometer. Fluorescence spectra were measured with a Varian CARY Eclipse Fluorescence Spectrophotometer. Spectral-grade solvents were used for measurements of UV-vis absorption and fluorescence.

\section{Synthesis of a new coumarin-based boronic acid as a potential} new sensor for saccharides

The 3-azido-7-hydroxycoumarin $\mathbf{1}$ and 3-azido-7-methoxycoumarin 2 were synthesised as reported in the literature (Ref. 13 and 37, and ESI $\dagger$ ) and used in the synthesis of compounds $\mathbf{4}$ and 5-P via the steps described below.

Synthesis of coumarin intermediate 4 . The coumarin fluorophore $3(0.41 \mathrm{~g}, 1.18 \mathrm{mmol})$ and $N$-Boc-ethylenediamine $(0.297 \mathrm{~g}, 1.85 \mathrm{mmol})$ were dissolved in DCM/MeOH and stirred at room temperature overnight. After crude NMR confirmed the imine formation, sodium borohydride $(0.089 \mathrm{~g}$, $1.42 \mathrm{mmol}$ ) was added to the reaction and stirred overnight. The reaction was quenched by water. After evaporating solvents, the residue was extracted with DCM and water. The organic layer was then dried with $\mathrm{Na}_{2} \mathrm{SO}_{4}$, filtered and evaporated to obtain the crude compound and then purified by flash column chromatography to give the coumarin intermediate 4 $(0.43 \mathrm{~g}, 74 \%)$ as a light brown solid, m.p. $120{ }^{\circ} \mathrm{C}$ (dec.). ${ }^{1} \mathrm{H}$ NMR $\left(\mathrm{CDCl}_{3}, \mathrm{ppm}\right) \delta 1.38(\mathrm{~s}, 9 \mathrm{H}), 2.72(\mathrm{~m}, 2 \mathrm{H}), 3.19(\mathrm{~m}, 2 \mathrm{H})$, $3.77(\mathrm{~s}, 2 \mathrm{H}), 3.86(\mathrm{~s}, 3 \mathrm{H}), 4.87(\mathrm{br}, \mathrm{NH}), 6.86(\mathrm{~d}, J=2.1 \mathrm{~Hz}, 1 \mathrm{H})$, $6.92(\mathrm{dd}, J=2.1,8.4 \mathrm{~Hz}, 1 \mathrm{H}), 7.34(\mathrm{~d}, J=8.1 \mathrm{~Hz}, 2 \mathrm{H}), 7.52(\mathrm{~d}$, $J=8.4 \mathrm{~Hz}, 1 \mathrm{H}), 7.82(\mathrm{~d}, J=8.1 \mathrm{~Hz}, 2 \mathrm{H}), 8.52(\mathrm{~s}, 1 \mathrm{H}), 8.78(\mathrm{~s}$, 1H); IR $\left(\mathrm{cm}^{-1}\right)$ 837, 1244, 1610, 1703, 2980; ESI mass [M + H] $\mathrm{C}_{26} \mathrm{H}_{30} \mathrm{~N}_{5} \mathrm{O}_{5}$ calculated 492.2247 found 492.2210 .

Synthesis of the pinacol protected derivative of coumarin boronate 5-P. Coumarin intermediate $4(0.035 \mathrm{~g}, 0.07 \mathrm{mmol})$, 2-(bromomethyl)phenylboronic acid pinacol ester ${ }^{60}(0.025 \mathrm{~g}$, $0.085 \mathrm{mmol})$ and potassium carbonate $(0.02 \mathrm{~g}, 0.14 \mathrm{mmol})$ were dissolved in acetonitrile and heated to reflux overnight. When the reaction finished, most of the acetonitrile was evaporated and the residue was added into water to form a precipitate. The precipitate was washed with water, ether and dried under reduced pressure to give the coumarin based boronic acid pinacol ester 5-P $(0.050 \mathrm{~g}$, quantitative yield $)$ as a brown powder, m.p. $90{ }^{\circ} \mathrm{C}$ (dec). ${ }^{1} \mathrm{H}$ NMR $\left(\mathrm{CDCl}_{3}\right.$, ppm) $\delta$ 1.25-1.42 $(\mathrm{m}, 21 \mathrm{H}), 2.57(\mathrm{t}, J=5.4 \mathrm{~Hz}, 2 \mathrm{H}), 3.22(\mathrm{~m}, 2 \mathrm{H}), 3.60(\mathrm{~s}, 2 \mathrm{H})$, $3.62(\mathrm{~s}, 2 \mathrm{H}), 3.93(\mathrm{~s}, 3 \mathrm{H}), 6.93(\mathrm{~s}, 1 \mathrm{H}), 6.98(\mathrm{~d}, J=8.4 \mathrm{~Hz}, 1 \mathrm{H})$, 7.33-7.34 (m, 4H), $7.43(\mathrm{~d}, J=7.8 \mathrm{~Hz}, 2 \mathrm{H}), 7.59(\mathrm{~d}, J=8.4 \mathrm{~Hz}$, $1 \mathrm{H}), 7.88(\mathrm{~d}, J=7.8 \mathrm{~Hz}, 2 \mathrm{H}), 8.59(\mathrm{~s}, 1 \mathrm{H}), 8.85(\mathrm{~s}, 1 \mathrm{H}) ;{ }^{13} \mathrm{C}\left\{{ }^{1} \mathrm{H}\right\}$ NMR $\left(\mathrm{CDCl}_{3}, \mathrm{ppm}\right) \delta 24.8,25.00,28.4,28.5,29.7,46.0,56.0$, 83.7, 83.9, 100.7, 111.6, 114.1, 120.3, 125.7, 126.1, 126.2, 126.3, $127.6,128.8,129.5,129.8,130.0,130.5,131.3,133.6,135.5$,
136.3, 143.8, 154.7, 156.2, 163.8; IR $\left(\mathrm{cm}^{-1}\right)$ 953, 1152, 1381, 1599, 1729, 2889, 2981, 3658; ESI mass $[\mathrm{M}+\mathrm{H}] \mathrm{C}_{39} \mathrm{H}_{47} \mathrm{BN}_{5} \mathrm{O}_{7}$ calculated 708.3569 found $708.3567 ;{ }^{11} \mathrm{~B}$ NMR $\left(\mathrm{CDCl}_{3}, \mathrm{ppm}\right)$ $\delta 33.90$.

\section{Cell culture and fluorescence imaging}

HeLa, PC-3, J774.2 macrophages and FEK4 cell lines were purchased from American type culture collection (ATCC). Cells were grown as monolayers in T75 tissue culture flasks and cultured in Eagle's Minimum Essential Medium (EMEM) for HeLa and FEK4, Roswell Park Memorial Institute medium (RPMI) for PC-3, Dulbecco's Modified Eagle Medium (DMEM) supplemented with $10 \%$ foetal bovine serum (15\% foetal bovine serum for macrophage and FEK4), 1\% L-glutamine $(200 \mathrm{mM}), 0.5 \%$ penicillin/streptomycin $\left(10000 \mathrm{IU} \mathrm{mL}^{-1} /\right.$ $10000 \mathrm{mg} \mathrm{mL}^{-1}$ ). Cells were cultured at $37^{\circ} \mathrm{C}$ in a humidified atmosphere of $5 \% \mathrm{CO}_{2}$ in air and split once $70 \%$ confluence had been reached, using RPMI, DMEM or EMEM medium. All steps were performed in absence of phenol red. Once cells reached more than $70 \%$ confluence, the supernatant containing dead cell matter and excess protein was aspirated. The live adherent cells were then washed with $10 \mathrm{~mL}$ of phosphate buffer saline solution twice to remove any remaining media. Cells were incubated in $3 \mathrm{~mL}$ of trypsin solution $(0.25 \%$ trypsin) for 5 to $7 \mathrm{~min}$ at $37^{\circ} \mathrm{C}$. After trypsinisation, $6 \mathrm{~mL}$ of medium containing $10 \%$ serum medium was added to inactivate the trypsin and the solution was centrifuged for $5 \mathrm{~min}$ $\left(1000 \mathrm{rpm}, 25^{\circ} \mathrm{C}\right)$. The supernatant liquid was aspirated and $5 \mathrm{~mL}$ of serum medium was added to the cell matter left behind. Cells were counted using a haemocytometer and then seeded as appropriate. For microscopy, cells were seeded into glass-bottomed Petri dishes and incubated for $12 \mathrm{~h}$ for HeLa, $24 \mathrm{~h}$ for PC-3, macrophage and FEK4 to ensure adhesion. Cells were plated in $35 \mathrm{~mm}$ uncoated $1.5 \mathrm{~mm}$ thick glass-bottomed dishes as $3 \times 10^{5}$ cells per dish and incubated for at least $24 \mathrm{~h}$ prior to imaging experiment. Once cells attached firmly, cells were washed with $995 \mu \mathrm{L}$ Hank's Balanced Salt Solution (HBSS) five times and refilled with $995 \mu \mathrm{L}$ of serum-free medium (SFM), then in each case, $10 \mu \mathrm{L}$ of either a compound 5-P stock solution (10 mM in DMSO : PB 1:1) or the hybrid 5@ $\beta$-D-glucan $\left(1 \mathrm{mg} \mathrm{mL}^{-1}\right.$ dispersion in DMSO: PB 1:1) were added. Cells were incubated with compounds for 15 minutes at $37{ }^{\circ} \mathrm{C}$. Afterward, cells were washed with $995 \mu \mathrm{L}$ Hank's Balanced Salt Solution (HBSS) three times to rinse the compound remain in the medium and $995 \mu \mathrm{L}$ of SFM was added.

Once the cell dish was ready for the single photon confocal fluorescence imaging, cells were excited at $405 \mathrm{~nm}, 488 \mathrm{~nm}$ and $561 \mathrm{~nm}$ wavelength, then at each wavelength, there were five images captured namely a merged image, image between 420 and $480 \mathrm{~nm}$ wavelength, image between 516 and $530 \mathrm{~nm}$ wavelength, image between 615 and $650 \mathrm{~nm}$ wavelength and Differential Interference Contrast (DIC) image. The region of interest (ROI) was linked via a time-correlated single-photoncounting PC module SPC830 (Becker and Hickl) to generate the multiphoton excited image with the associated character- 
istic decay at each pixel position. The decays were subsequently analysed to generate the FLIM image.

Two-photon (710-1000 nm) wavelength laser light was obtained from the mode-locked titanium-sapphire laser Mira (Coherent Laser Co., Ltd) producing 180 femtosecond at 75 MHz. This laser-pumped solid-state continuous wave $532 \mathrm{~nm}$ laser (Verdi V18, Coherent Laser Co., Ltd). This can also be used for the fundamental output of the oscillator $810 \pm$ $2 \mathrm{~nm}$. The laser beam was focused to a diffraction-limited spot by the water immersion UV objective (Nikon VC×60, NA1.2) at the specimen on a microscope stage of the modified Nikon TE2000-U. The focused laser multiphoton beam was raster scanned using a modified Nikon Eclipse EC2 scan head to allow input of the Titanium: sapphire laser Fluorescence emission was collected without de-scanning, bypassing the scanning system and passed through a coloured glass (BG39) filter. In normal operation mode and line scan frame and pixel clock signal was generated and synchronised with an external fast microchannel plate photomultiplier tube as detector (R3809 U, Hamamatsu, Japan). These were linked via a TimeCorrelated Single Photon Counting (TCSPC) PC module SPC830 for the lifetime measurements with $810 \mathrm{~nm}$ excitation and emission in the range between 360 and $580 \mathrm{~nm}$. FLIM images are shown with corresponding intensity images from the same samples with different coded colours representing different lifetime scales. The lifetime of each pixel is obtained by applying a single or multi-exponential fit.

\section{Conflicts of interest}

There are no conflicts to declare.

\section{Acknowledgements}

This work was supported by funding from ERC Consolidator grant O2Sense, STFC, MRC, EPSRC, the Royal Society and The University of Bath to SIP. Dr Z. Hu (Bath University, PhD 2012) is thanked for some of the preliminary titration experiments. TDJ wishes to thank the Royal Society for a Wolfson Research Merit Award.

\section{Notes and references}

1 R. A. Sarteshnizi, H. Hosseini, D. Bondarianzadeh and F. J. Colmenero, LWT - Food Sci. Technol., 2015, 62, 704710.

2 A. B. C. Samuelsen, J. Schrezenmeir and S. H. Knutsen, Mol. Nutr. Food Res., 2014, 58, 183-193.

3 R. Pillai, M. Redmond and J. Röding, Int. J. Cosmet. Sci., 2005, 27, 292-292.

4 T. Suzuki, S. Nakamura, S. Nakayama and K. Nishikawa, Google Patents, US patent, US20050271613A1, 2005.

5 J. Hwang, K. Lee, A. A. Gilad and J. Choi, Biotechnol. Bioprocess Eng., 2018, 23, 144-149.
6 Z. Mirza, E. R. Soto, F. Dikengil, S. M. Levitz and G. R. Ostroff, in Vaccines for Invasive Fungal Infections: Methods and Protocols, ed. M. Kalkum and M. Semis, Springer, New York, New York, NY, 2017, pp. 143-157.

7 E. Soares, S. Jesus and O. Borges, Int. J. Pharm., 2018, 535, 261-271.

8 E. Soares, S. Jesus and O. Borges, Eur. J. Pharm. Biopharm., 2018, 131, 33-43.

9 K. Miyoshi, K. Uezu, K. Sakurai and S. Shinkai, Chem. Biodivers., 2004, 1, 916-924.

10 P. Jalal, S. Fatemeh, T. Farahnaz, G. Ruhollah, E. Hossein Ali and D. Ezzat, Hum. Exp. Toxicol., 2010, 30, 173-181.

11 X. Guan, X. Hu, S. Liu, X. Sun and X. Gai, RSC Adv., 2016, 6, 1151-1157.

12 (a) H. Ge, P. J. Riss, V. Mirabello, D. G. Calatayud, S. E. Flower, R. L. Arrowsmith, T. D. Fryer, Y. Hong, S. Sawiak, R. M. J. Jacobs, S. W. Botchway, R. M. Tyrrell, T. D. James, J. S. Fossey, J. R. Dilworth, F. I. Aigbirhio and S. I. Pascu, Chem, 2017, 3, 437-460; (b) D. G. Calatayud, H. Ge, N. Kuganathan, V. Mirabello, R. M. J. Jacobs, N. H. Rees, C. T. Stoppiello, A. N. Khlobystov, R. M. Tyrrell, E. Da Como and S. I. Pascu, ChemistryOpen, 2018, 7(2), 144-158.

13 X. Sun, W. Zhai, J. S. Fossey and T. D. James, Chem. Commun., 2016, 52, 3456-3469.

14 G. C.-F. Chan, W. K. Chan and D. M.-Y. Sze, J. Hematol. Oncol., 2009, 2, 25-25.

15 Z. H. Ping, H. Xu, T. Liu, J. C. Huang, Y. Meng, X. J. Xu, W. H. Li and L. N. Zhang, J. Mater. Chem. B, 2016, 4, 45654573.

16 A. Choromanska, J. Kulbacka, N. Rembialkowska, J. Pilat, R. Oledzki, J. Harasym and J. Saczko, Int. J. Biol. Macromol., 2015, 80, 23-28.

17 Y. H. Gu, Y. Takagi, T. Nakamura, T. Hasegawa, I. Suzuki, M. Oshima, H. Tawaraya and Y. Niwano, J. Med. Food, 2005, 8, 154-158.

18 T. J. Yoon, S. Koppula and K. H. Lee, Anticancer Agents Med. Chem., 2013, 13, 699-708.

19 H. Volpato, D. B. Scariot, E. F. P. Soares, A. P. Jacomini, F. A. Rosa, M. H. Sarragiotto, T. Ueda-Nakamura, A. F. Rubira, G. M. Pereira, R. Manadas, A. J. Leitão, O. Borges, C. V. Nakamura and M. d. C. Sousa, Int. J. Biol. Macromol., 2018, 119, 1264-1275.

20 A. C. Sedgwick, R. S. L. Chapman, J. E. Gardiner, L. R. Peacock, G. Kim, J. Yoon, S. D. Bull and T. D. James, Chem. Commun., 2017, 53, 10441-10443.

21 A. C. Sedgwick, H. H. Han, J. E. Gardiner, S. D. Bull, X. P. He and T. D. James, Chem. Sci., 2018, 9, 3672-3676.

22 A. C. Sedgwick, J. E. Gardiner, G. Kim, M. Yevglevskis, M. D. Lloyd, A. T. A. Jenkins, S. D. Bull, J. Yoon and T. D. James, Chem. Commun., 2018, 54, 4786-4789.

23 D. Wu, A. C. Sedgwick, T. Gunnlaugsson, E. U. Akkaya, J. Yoon and T. D. James, Chem. Soc. Rev., 2017, 46, 71057123.

24 S. Tamesue, M. Numata, K. Kaneko, T. D. James and S. Shinkai, Chem. Commun., 2008, 4478-4480. 
25 Z. Liu, D. Wang, X. Sun, Q. Sun, Y. Wu and Y. Xu, Int. J. Mol. Sci., 2018, 19, 3323.

26 M. P. Alexander, S. N. Fiering, G. R. Ostroff, R. A. Cramer and D. W. Mullins, Cancer Immunol. Immunother., 2018, 67, 1731-1742.

27 K. Sivakumar, F. Xie, B. M. Cash, S. Long, H. N. Barnhill and Q. Wang, Org. Lett., 2004, 6, 4603-4606.

28 M. Li, H. Ge, V. Mirabello, R. L. Arrowsmith, G. KociokKohn, S. W. Botchway, W. Zhu, S. I. Pascu and T. D. James, Chem. Commun., 2017, 53, 11161-11164.

29 S.-Y. Xu, X. Sun, H. Ge, R. L. Arrowsmith, J. S. Fossey, S. I. Pascu, Y.-B. Jiang and T. D. James, Org. Biomol. Chem., 2015, 13, 4143-4148.

30 M. Li, H. Ge, R. L. Arrowsmith, V. Mirabello, S. W. Botchway, W. Zhu, S. I. Pascu and T. D. James, Chem. Commun., 2014, 50, 11806-11809.

31 K. Effenberger-Neidnicht, S. Breyer, K. Mahal, R. Schobert, R. Diestel and F. Sasse, ChemBioChem, 2011, 12, 12371241.

32 D. Soriano Del Amo, W. Wang, H. Jiang, C. Besanceney, A. C. Yan, M. Levy, P. Wu, F. L. Marlow and Y. Liu, J. Am. Chem. Soc., 2010, 132, 16893-16899.

33 A. R. Lippert, E. J. New and C. J. Chang, J. Am. Chem. Soc., 2011, 133, 10078-10080.

34 W. Xuan, C. Sheng, Y. Cao, W. He and W. Wang, Angew. Chem., Int. Ed., 2012, 51, 2282-2284.

35 F. D’Hooge, S. A. Elfeky, S. E. Flower, S. I. Pascu, A. T. A. Jenkins, J. M. H. v. d. Elsen, T. D. James and J. S. Fossey, RSC Adv., 2012, 2, 3274-3280.

36 P. A. Waghorn, M. W. Jones, M. B. M. Theobald, R. L. Arrowsmith, S. I. Pascu, S. W. Botchway, S. Faulkner and J. R. Dilworth, Chem. Sci., 2013, 4, 1430-1441.

37 X. Wu, Z. Li, X.-X. Chen, J. S. Fossey, T. D. James and Y.-B. Jiang, Chem. Soc. Rev., 2013, 42, 8032-8048.

38 Y. B. Wu, H. M. Guo, X. Zhang, T. D. James and J. Z. Zhao, Chem. - Eur. J., 2011, 17, 7632-7644.

39 S. A. Elfeky, S. E. Flower, N. Masumoto, F. D’Hooge, L. Labarthe, W. B. Chen, C. Len, T. D. James and J. S. Fossey, Chem. - Asian J., 2010, 5, 581-588.

40 E. Galbraith and T. D. James, Chem. Soc. Rev., 2010, 39, 3831-3842.

41 Y. J. Huang, Y. B. Jiang, S. D. Bull, J. S. Fossey and T. D. James, Chem. Commun., 2010, 46, 8180-8182.

42 J. S. Fossey, F. D'Hooge, J. M. H. van den Elsen, M. P. Pereira Morais, S. I. Pascu, S. D. Bull, F. Marken, A. T. A. Jenkins, Y.-B. Jiang and T. D. James, Chem. Rec., 2012, 12, 464-478.

43 S. Jabbari-Farouji and P. van der Schoot, J. Chem. Phys., 2012, 137, 064906.
44 P. Thordarson, Chem. Soc. Rev., 2011, 40, 1305-1323.

45 B. Mao, D. G. Calatayud, V. Mirabello, N. Kuganathan, H. Ge, R. M. J. Jacobs, A. M. Shepherd, J. A. Ribeiro Martins, J. Bernardino De La Serna, B. J. Hodges, S. W. Botchway and S. I. Pascu, Chem. - Eur. J., 2017, 23, 9772-9789.

46 C. A. Hunter and H. L. Anderson, Angew. Chem., Int. Ed., 2009, 48, 7488-7499.

47 A. Stephenson-Brown, S. Yong, M. H. Mansor, Z. Hussein, N.-C. Yip, P. M. Mendes, J. S. Fossey and F. J. Rawson, Chem. Commun., 2015, 51, 17213-17216.

48 M. Lledos, V. Mirabello, S. Sarpaki, H. Ge, J. Smugowski Hubert, L. Carroll, O. Aboagye Eric, I. Aigbirhio Franklin, W. Botchway Stanley, R. Dilworth Jonathan, G. Calatayud David, K. Plucinski Pawel, J. Price Gareth and I. Pascu Sofia, ChemNanoMat, 2018, 4, 361-372.

49 A. A. R. Mota, P. H. P. R. Carvalho, B. C. Guido, H. C. B. de Oliveira, T. A. Soares, J. R. Correa and B. A. D. Neto, Chem. Sci., 2014, 5, 3995-4003.

50 I. Rivolta, A. Panariti, B. Lettiero, S. Sesana, P. Gasco, M. R. Gasco, M. Masserini and G. Miserocchi, J. Physiol. Pharmacol., 2011, 62, 45.

51 T. Matsumoto, M. Numata, T. Anada, M. Mizu, K. Koumoto, K. Sakurai, T. Nagasaki and S. Shinkai, Biochim. Biophys. Acta, 2004, 1670, 91-104.

52 M. Bradley, L. Alexander and R. M. Sanchez-Martin, J. Fluoresc., 2008, 18, 733-739.

53 J. A. Tyson, V. Mirabello, D. G. Calatayud, H. Ge, G. KociokKöhn, S. W. Botchway, G. Dan Pantoş and S. I. Pascu, Adv. Funct. Mater., 2016, 26, 5641-5657.

54 J. Richardson, L. Steinmetz, S. Deutscher, W. Bookless and W. Schmelzinger, Z. Naturforsch., 1978, 33, 1592-1593.

55 A. S. Kristoffersen, S. R. Erga, B. Hamre and Ø. Frette, J. Fluoresc., 2014, 24, 1015-1024.

56 A. Shivalingam, M. A. Izquierdo, A. Le Marois, A. Vyšniauskas, K. Suhling, M. K. Kuimova and R. Vilar, Nat. Commun., 2015, 6, 8178.

57 J. Sturala, M. K. Etherington, A. N. Bismillah, H. F. Higginbotham, W. Trewby, J. A. Aguilar, E. H. C. Bromley, A.-J. Avestro, A. P. Monkman and P. R. McGonigal, J. Am. Chem. Soc., 2017, 139, 1788217889.

58 H. Noothalapati, T. Sasaki, T. Kaino, M. Kawamukai, M. Ando, H.-o. Hamaguchi and T. Yamamoto, Sci. Rep., 2016, 6, 27789.

59 M. A. Musa, J. S. Cooperwood and M. O. F. Khan, Curr. Med. Chem., 2008, 15, 2664-2679.

60 D. K. Scrafton, J. E. Taylor, M. F. Mahon, J. S. Fossey and T. D. James, J. Org. Chem., 2008, 73, 2871-2874. 